\title{
Prevalence and associated factors of home delivery among women at Jimma town, Jimma Zone, Southwest Ethiopia
}

\begin{abstract}
Background: Maternal and child mortality and morbidity are higher during childbirth in developing countries compared to developed countries. Institutional delivery service utilization is indispensable to improve maternal and child health.However, the proportion of women utilizing institutional delivery service in Ethiopia is very low. In addition, little is known about factors contributing to home delivery.
\end{abstract}

Objectives: To assess the prevalence of home delivery and associated risk factors at Jimma Town, Southwest Ethiopia.

Methods: A community-based cross-sectional study was employed on 423 study participants. Data were collected by semi-structured questionnaire through face to face interview. A systematic sampling technique was used to select study participants. After cleaning and checking completeness of collected data, data was entered into Epi data version 3.3.1 software and exported to Statistical Package for the Social Science (SPSS) version 21.0 for analysis. Logistic regression was used to find out the association between explanatory and response variables. Explanatory variables which fulfill the assumption of logistic regression and had a P-value less than 0.25 from bi-variable logistic regression were considered for the multivariable logistic regression model. The strength of association was evaluated using odds ratio at $95 \%$ confidence interval $(\mathrm{CI})$ and $\mathrm{P}$-value $<0.05$ was considered to declare significant associations.

Results: The prevalence of home delivery in this study was $36.64 \%$ ( $\mathrm{n}=155 / 423$ and it had significant association with illiteracy AOR $=2.7$ [ $(95 \% \mathrm{CI}) ;(1.37-5.43)]$, multi-gravida $\mathrm{AOR}=2.12[(95 \% \mathrm{CI}) ;(1.09-4.10)]$, history of antenatal care $(\mathrm{ANC})$ follow up $\mathrm{AOR}=4.15$ $[(95 \% \mathrm{CI}) ;(2.57-6.70)]$ and husband educational status AOR $=13.5[(95 \% \mathrm{CI}) ;(2.86-63.62)]$.

Conclusion: The prevalence of home delivery in this study was high compared to world health organizational recommendation. Educational status of the mother, gravida, antenatal care follow up and husband educational status were factors that had a significant association. Women empowerment through educational opportunities, increase antenatal care follow up and male involvement in maternal health service are recommended.
Volume 6 Issue 4 - 2020

\author{
Aynalem Yetwale, Eneyew Melkamu,Workiltu \\ Ketema \\ School of nursing and midwifery, faculty of health sciences, \\ institute of health, Jimma University, Ethiopia
}

\begin{abstract}
Correspondence: Aynalem Yetwale, School of nursing and midwifery, faculty of health sciences, institute of health, Jimma University, Ethiopia, Tel +25 I9/298 I I54, Email aynalemyetwale@gmail.com
\end{abstract}

Received: March 09, 2020 | Published: August 25, 2020

\section{Introduction}

Maternal morbidity and mortality is a global health problem. Most of the maternal death occurs in developing country. ${ }^{1}$ Maternal mortality defined as "death of women while pregnant or within 42 days of termination of pregnancy, irrespective of the duration and sites of the pregnancy, from any cause related to or aggravated by pregnancy and its management but not from accidental cases. ${ }^{2}$ Different factors can contribute to maternal and neonatal death. However, the majority of maternal mortality and morbidity are due to preventable causes which can be detected and treated early during antenatal care (ANC) and intra-partum period. ${ }^{3}$ Giving birth at home is among the factors which associated with maternal and neonatal mortality and morbidity. Studies showed that, the majority of home deliveries in developing countries are unplanned, accidental and supported by unskilled health professionals. When a women give birth at home, it may have adverse neonatal and maternal outcomes ${ }^{4}$ like, increases the risk of infection, postpartum hemorrhage (PPH), and transmission of HIV/AIDS to relatives or traditional birth attendants, who conduct deliveries without protective equipments. ${ }^{5}$ The presence of skilled delivery service utilization at each birth can significantly reduce maternal morbidity and mortality. ${ }^{6,7}$

During the past fifteen years, the Federal Ministry of Health (FMoH) of Ethiopia has built an impressive framework for improving health for all, including maternal and neonatal health. There are strategies for free maternal and child health services. Activities include deploying Health Officers with MSc training in Integrated Emergency Obstetrics and Surgery (IEOS), increasing the number of BSc and MSc midwife professionals, improving the availability of safe blood and pharmaceutical supplies and a strong referral system, providing short term training like basic emergency obstetric\& newborn care (BEMONC) and Comprehensive Emergency Obstetric and Newborn Care $(\mathrm{EMONC}){ }^{8}$ In addition to these activities, Tigray region has undertaken different activities to increase institutional delivery, ${ }^{9}$ including establishing a new structure at the community level known as "Women Development Army" which enables women to talk about pregnancy and delivery, making health facilities more women friendly, 
opening of maternity waiting area at health institutions, increasing the number of ambulance services and availing of traditional ambulances for early referrals in case of emergencies. ${ }^{9}$ Despite these efforts, the rate of home delivery is still high.

Despite the declining pattern of maternal mortality in Ethiopia, maternal mortality ratio remains high, ranging from 266-1667 per 100,000 Live Births (LB). ${ }^{10}$ The study site and Jimma zone is part of a region where such a high maternal mortality rate has been reported although it has a declining pattern. There is no sample data on home delivery and associated risk factors in the study area. To this effect, this study is aimed at establishing the proportion of home deliveries and assessing factors associated with home deliveries in Jimma town, Southwest Ethiopia.

The objectives of the study

I. To assess the prevalence of home delivery among women at Jimma town, Jimma zone, Southwest Ethiopia

II. To determine factors associated with home delivery practice among women at Jimma town, Southwest Ethiopia

\section{Methodology}

\section{Study design and population}

Community based cross sectional study design was conducted in Jimma town, Jimma zone, Oromia region, Southwest Ethiopia from June to October 2019. It is located $355 \mathrm{~km}$ far from Addis Ababa, the capital city of Ethiopia. Geographically, the study site is found at latitude and longitude of $7^{\circ} 40^{\prime} \mathrm{N} 36^{\circ} 50^{\prime} \mathrm{E} / 7.667^{\circ} \mathrm{N} 36.833^{\circ} \mathrm{E} / 7.667 ; 36.833$ and altitude of 1780 meter above sea level. The annual temperature of the study area is generally characterized by warm climate with a mean annual maximum temperature of $30^{\circ} \mathrm{C}$ and a mean annual minimum temperature of $14^{\circ} \mathrm{C}$ ranging between $26-38^{\circ} \mathrm{C}$. The town is divided into 13 kebele's districts with a total population of $130,254 .{ }^{4}$ In the town, there are two hospitals (one referral and the other general), and four public health centers. Majority of the residents of the study area are merchants and government employers occupationally. Women living in the selected area and gave birth within the last two years were eligible to participate in the study and women who are critically ill were excluded from the study.

\section{Sample size and sampling techniques}

Sample size of the study was calculated following a single population sample size calculation formula. Considering $50 \%$ prevalence of home delivery, \pm 5 precision, and $5 \%$ sampling error, a total of 384 samples were enrolled in the study. The formula was;

$$
n=Z^{2} \alpha{ }_{2} P Q d^{2}
$$

Where: $\mathrm{n}$, sample size; $\mathrm{Z}$, critical value of $95 \% \mathrm{CI}(1.96) ; \alpha$, level of significance $(\alpha=0.05) ; \mathrm{P}$, proportion of population $(0.5) ; \mathrm{Q}, 1-\mathrm{P}$; $\mathrm{P}, 0.5 ; \mathrm{Q}, 0.5 ; \mathrm{d}$, margin of error $(0.05)$

$$
n=\frac{(1.96)^{2} * 0.5 * 0.5}{(0.05)^{2}}=384
$$

Considering a contingency of $10 \%, 39$ more women were added and a total of 423 women were enrolled in the study. Jimma town has 13 kebeles and from those kebeles, 4 kebeles were randomly selected. Proportional allocation was employed for each kebele and a systematic sampling technique was used to select study participants.

\section{Data collection methods and tools}

\section{Data collection methods}

Data were collected by face to face interview through semistructured and pretested questionnaire. The questionnaire has two parts, the first assessing socio-demographic characteristics and the second part assessing obstetric history of mothers. The tool was first prepared in English and then translated to local language (Afan Oromo). Three data collectors and two supervisors were selected and one-day training was given about the methodology and questionnaire by the investigator.

\section{Data quality control mechanism}

Data quality control was maintained before, during and after data collection. Before data collection, the questionnaire was translated into local language and pretest was done on 5\% (21) of sample size at Mandera kochi and necessary modifications including wordings were made on the questionnaire before it was applied to the study population. One day training was given for data collectors and supervisors on the objectives, methodology and on the data collection technique. During data collection, close follow up was made by supervisors. After data collection, data were cleaned and checked for its completeness and the data were entered in Epi data version 3.1.1 to point out errors made during data collection automatically then transferred to SPSS version 21.0 (Figure 1).

\section{Prevalence of home delivery}

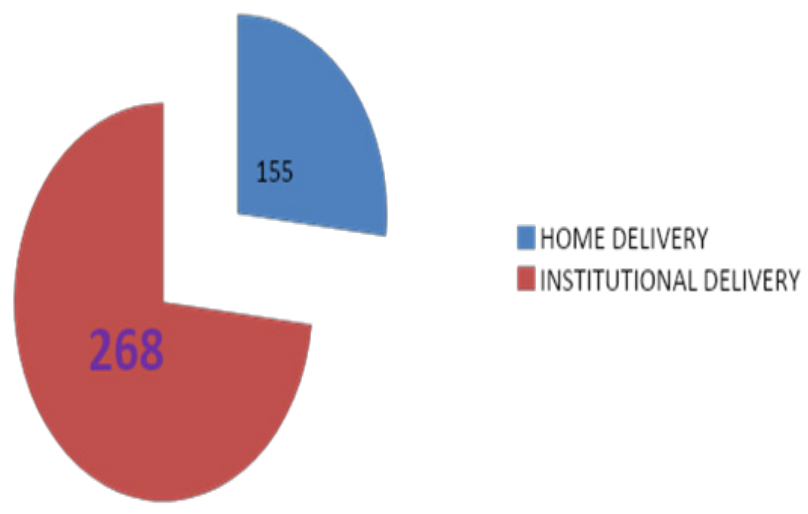

Figure I prevalence of home delivery at Jimma Town, Southwest Ethiopia, 2018/19.

\section{Study variables}

\section{Independent variables}

a. Socio-demographic characteristics: age, religion, marital status, educational status, etc...

b. Obstetric characteristics including history of abortion, history of stillbirth, ANC visit, Number of ANC visit,Reasons of ANC visit, Advice received during ANC about place of birth, Reasons for not having ANC follow up, Place of delivery, Delivery assistant, and Gravida

c. Dependent variables

d. Home delivery 


\section{Data analysis}

Data were entered into Epi data version 3.3.1 software after coding and checking their completeness and exported to statistical package for social science (SPSS) version 21.0 for analysis. Descriptive analysis (frequencies, percentage, means and standard deviations) was done to explore socio-demographic characteristics and obstetric history of study participants.Binary Logistic regression was used to find out the association between home delivery and explanatory variables. Explanatory variables that had a P-value less than 0.25 and fulfill the assumption of logistic regression from bi-variable logistic regression were considered for the multivariable logistic regression model. The strength of association was evaluated using odds ratio at $95 \%$ confidence interval and $\mathrm{P}$-value $<0.05$ was considered to declare significant associations.

\section{Results}

\section{Socio-demographic characteristics of women}

A total of 423 study participants were involved in this study. Majority of study participants were found in the age range between 20 to 34 years. $376(88.9 \%)$ participants were married and $202(47.8 \%)$ were Muslims. The participants stated that majority of them $(86.3 \%)$ did not receive health education on maternal health (Table 1 ).

Table I Socio-demographic characteristics of the mothers who gave birth in the last two years at Jimma Town, Southwest Ethiopia, 20 I8/I9

\begin{tabular}{|c|c|c|c|}
\hline Variables & & Frequency & Percent \\
\hline \multirow[t]{6}{*}{ Age } & $15-19$ & 53 & 12.5 \\
\hline & $20-24$ & 184 & 43.5 \\
\hline & $25-29$ & 129 & 30.5 \\
\hline & $30-34$ & 44 & 10.4 \\
\hline & $35-39$ & II & 2.6 \\
\hline & 40 and above & 13 & 3.1 \\
\hline \multirow[t]{3}{*}{ Marital status } & Married & 376 & 88.9 \\
\hline & Divorced & 30 & 7.09 \\
\hline & Widowed & 16 & 3.78 \\
\hline \multirow[t]{4}{*}{ Religion } & Muslim & 202 & 47.8 \\
\hline & Orthodox & 102 & 24.1 \\
\hline & Protestant & 97 & 22.9 \\
\hline & Others & 22 & 5 \\
\hline \multirow[t]{4}{*}{ Educational Status } & Illiterate & 74 & 17.5 \\
\hline & Primary school complete & 152 & 35.9 \\
\hline & High school complete & $|4|$ & 33.3 \\
\hline & Tertiary education & 56 & 13.2 \\
\hline \multirow[t]{4}{*}{ Husband education } & Illiterate & 33 & 7.8 \\
\hline & Primary school complete & 143 & 33.8 \\
\hline & High school complete & 167 & 39.5 \\
\hline & Tertiary education & 80 & 18.9 \\
\hline \multirow[t]{2}{*}{ Received health education on maternal health } & Yes & 58 & 13.7 \\
\hline & No & 365 & 86.3 \\
\hline
\end{tabular}

\section{Obstetric characteristics of the women}

Regarding obstetric characteristics of study participants, majority of them had neither history of abortion $(92.43 \%)$ nor stillbirth (97.16\%). 268 (63.36\%) study participants visit ANC during their last pregnancy and 261(97.39) get advice received during ANC about place of birth. For most of the women (86.94\%), reasons for visiting ANC were regular checkup. For majority of respondents, reasons they mentioned for not going to ANC were being busy with other work (43.23\%), (Tables 2\&3). 
Table 2 Obstetric characteristics of the mothers who gave birth in the last two years at, Jimma Town, Southwest Ethiopia, 20 I8/I9

\begin{tabular}{|c|c|c|c|}
\hline Variables & Response options & Frequency & Percent \\
\hline \multirow[t]{2}{*}{ History of abortion } & Yes & 32 & 7.565 \\
\hline & No & 391 & 92.43 \\
\hline \multirow[t]{2}{*}{ History of stillbirth } & Yes & 12 & 2.837 \\
\hline & No & 411 & 97.16 \\
\hline \multirow[t]{2}{*}{ ANC visit } & Yes & 268 & 63.36 \\
\hline & No & 155 & 36.64 \\
\hline \multirow[t]{3}{*}{ Number ofANC visit } & One & 58 & 21.64 \\
\hline & Two & 163 & 60.82 \\
\hline & Three or more & 47 & 17.54 \\
\hline \multirow[t]{2}{*}{ Reasons for ANC visit } & Regular check-up & 233 & 86.94 \\
\hline & Due to illness & 35 & 13.06 \\
\hline \multirow[t]{2}{*}{ Advice received during ANC about place of birth } & Yes & 261 & 97.39 \\
\hline & No & 7 & 2.612 \\
\hline \multirow[t]{4}{*}{ Reasons for not having ANC follow up } & No illness with pregnancy & $4 I$ & 26.45 \\
\hline & Busy work schedule & 67 & 43.23 \\
\hline & Lack of knowledge & 28 & 18.06 \\
\hline & Distant health facilities & 19 & 12.26 \\
\hline \multirow[t]{2}{*}{ Place of delivery } & Home & 155 & 36.4 \\
\hline & Health institution & 268 & 63.6 \\
\hline \multirow[t]{2}{*}{ Delivery assistant at home } & Family member & 43 & 27.7 \\
\hline & Traditional birth attendant & 112 & 72.3 \\
\hline \multirow[t]{3}{*}{ Gravida } & 1 & 97 & 22.93 \\
\hline & 4-Feb & 283 & 66.9 \\
\hline & 5 or more & 43 & 10.17 \\
\hline
\end{tabular}

Table 3 Factors associated with home delivery at Jimma Town, Southwest Ethiopia, 20 I8/I 9

\begin{tabular}{|c|c|c|c|c|c|c|c|}
\hline \multirow[b]{2}{*}{ Variables } & & \multicolumn{2}{|c|}{ Home delivery } & \multirow[t]{2}{*}{ COR } & \multirow[t]{2}{*}{ P. value } & \multirow[t]{2}{*}{ AOR (95\%Cl) } & \multirow[t]{2}{*}{ P. value } \\
\hline & & Yes & No & & & & \\
\hline \multirow[t]{2}{*}{ Age(Years) } & $<30$ & $14 \mid$ & 255 & 1 & & & \\
\hline & $>30$ & 14 & 13 & $0.5 I(0.23-I . \mid 2)$ & 0.95 & I.74(0.7I-4.27) & 0.22 \\
\hline \multirow[t]{2}{*}{ Marital status } & Married & 142 & 235 & I & & & \\
\hline & Single & 13 & 33 & $0.65(0.33-1.28)$ & 0.214 & $0.72(0.32-1.6 I)$ & 0.042 \\
\hline \multirow[t]{2}{*}{ Maternal educational status } & Illiterate & 51 & 23 & $5.22(3.03-8.99)$ & 0 & $2.73(1.37-5.43)$ & $0.04 *$ \\
\hline & Literate & 104 & 245 & I & & & \\
\hline \multirow[t]{2}{*}{ Gravida } & Primi- gravida & 18 & 82 & 1 & & & \\
\hline & Multi-gravida & 137 & 186 & $3.35(1.92-5.85)$ & 0 & $2.12(1.09-4.10)$ & $0.02 *$ \\
\hline \multirow[t]{2}{*}{ ANC follow-up } & Yes & 94 & 61 & 1 & & & \\
\hline & No & 61 & 207 & $5.22(3.40-8.04)$ & 0 & $4.15(2.57-6.70)$ & $0.00 *$ \\
\hline \multirow[t]{2}{*}{ Husband education status } & Illiterate & 26 & 7 & $7.52(3.17-17.77)$ & 0 & $13.5(2.86-63.62)$ & $0.00 I^{*}$ \\
\hline & Literate & 155 & 268 & I & I & & \\
\hline
\end{tabular}




\section{Prevalence of home delivery}

Among women involved in the study, 36.64\% $(\mathrm{n}=155 / 423)$ had a practice of home delivery.

\section{Factors associated with home delivery}

In this study, educational status of the mother was significantly associated with home delivery. Mothers with illiterate educational status were 2.7 times more likely to give birth at home than mothers with literate in educational status $\mathrm{AOR}=2.7$ [(95\% CI); (1.37-5.43)]. Another explanatory variable that had an association with home delivery was gravida. Multigravida mothers were 2.12 times more prone to home delivery than primi-gravida $\mathrm{AOR}=2.12[(95 \% \mathrm{CI})$; (1.09-4.10)]. Study participants who had no history of ANC follow up were 4.15 times more likely to give birth at home than mothers who had ANC follow up AOR=4.15 [(95\%CI); (2.57-6.70)]. On the other hand, study participants whose husbands are illiterate were 13.5 times more prone to give birth at home than mother with literate husband $\mathrm{AOR}=13.5[(95 \% \mathrm{CI}) ;(2.86-63.62)]$.

\section{Discussion}

The prevalence of home delivery in this study was $36.64 \%$. This study is almost similar to a study done in Mizan-Aman Town, Southwest Ethiopia $(33.5 \%)^{11}$ and Delanta district $(35.2 \%) .{ }^{12}$ However, the prevalence of this study was lower than research done from western Nepal 41.9\%, ${ }^{13}$ in Zala Woreda (77\%), ${ }^{14}$ Ayssaita, Afar, Ethiopia-2016 $(71 \%),{ }^{15}$ in Gozamin District, Northwest Ethiopia $(75.3 \%)^{16}$ and Nigeria(69.5\%). ${ }^{17}$ This variation may be due to differences in sociodemographic status, sample size and study period. On the contrary, the prevalence of home delivery in this study was higher than the study done in Brazilian (11.7\%). ${ }^{18}$ The difference may be due to sociodemographic and methodological variation.

In this study, educational status of mothers was significantly associated with home delivery. Mothers with illiterate educational status were 2.7 times more likely to give birth at home than mothers with literate in educational status $\mathrm{AOR}=2.7$ [(95\%CI); (1.375.43)]. This study is supported by a study done in Delanta district, ${ }^{12}$ Gozamen district, ${ }^{16}$ Ayssaita, Afar, Ethiopia-2016, ${ }^{15}$ in Zala Woreda ${ }^{14}$ and Nepal. ${ }^{15}$ This may be due to non-educated women might not have decision-making power on seeking health services, or have the ability to travel outside the home; they are more exposed to family pressure and cultural influences.Another explanatory variable that had association with home delivery was gravida. Mothers with a history of multigravida were 2.12 times more prone to home delivery than primigravida $\mathrm{AOR}=2.12[(95 \% \mathrm{CI}) ;(1.09-4.10)]$. This study is in line with a study done in Nepal. ${ }^{13}$ This may be due to multi-gravida mothers may consider themselves as experienced for labour and less risk for complication.

Study participants who had no history of ANC follow up were 4.15 times more likely to give birth at home than mothers who had ANC follow up AOR=4.15 [(95\% CI); (2.57-6.70)]. Which is consistent to study done in Delanta district, ${ }^{12}$ in Zala Woreda, ${ }^{14}$ and Nigeria.This is may be due to mothers who had ANC visits had a chance to know the importance of institutional delivery.On the other hand, study participants with whose husbands are illiterate were 13.5 times more prone to give birth at home than mothers whose husbands are literate in educational status AOR $=13.5[(95 \% \mathrm{CI}) ;(2.86-63.62)]$. This study is supported by the study done in Nigeria ${ }^{17}$ and Nepal. ${ }^{13}$ This may be due to educated husbands may recognize the importance of institutional delivery and involve in the use of maternal health services.

\section{Conclusion}

The prevalence of home delivery in this study was high compared with world health organization recommendation. Educational status of mother, gravida, ANC follow up and husband educational status were factors that had a significant association. Women empowerment through educational opportunities, increase antenatal care follow up and male involvement in maternal health service are recommended.

\section{Acknowledgments}

None.

\section{Conflicts of interest}

Author declare that there is no conflict of interest.

\section{Funding}

None.

\section{References}

1. Organization WHO. Trends in maternal mortality: 1990 to 2010: WHO, UNICEF, UNFPA and The World Bank estimates. 2012.

2. Khan KS, Wojdyla D, Say L, et al. WHO analysis of causes of maternal death: a systematic review. The lancet. 2006;367(9516):1066-1074.

3. Health FMo. Management protocol on selected obstetrics topics. Federal Democratic Republic of Ethiopia. 2010:8-68.

4. Moindi RO, Ngari MM, Nyambati VC, et al. Why mothers still deliver at home: understanding factors associated with home deliveries and cultural practices in rural coastal Kenya, a cross-section study. BMC Public Health. 2015;16(1):114.

5. Belemsaga DY, Goujon A, Kiendrebeogo JA, et al. A review of factors associated with the utilization of healthcare services and strategies for improving postpartum care in Africa. Afrika Focus. 2015;28(2):83.

6. Ransom E, Yinger N. Making Motherhood Safer: Overcoming Obstacles on the Pathway to Care. 2002: Population Reference Bureau. 2002.

7. Abou Zahr C, Wardlaw TM, Choi Y. Maternal mortality in 2000: estimates developed by WHO, UNICEF and UNFPA: World Health Organization; 2004.

8. Mirkuzie AH, Sisay MM, Reta AT, et al. Current evidence on basic emergency obstetric and newborn care services in Addis Ababa, Ethiopia; a cross sectional study. BMC pregnancy and childbirth. 2014;14(1):354.

9. Giorgi G, Krishnan K. Health Needs Assessment for Mekelle City, Ethiopia; 2009.

10. Tessema GA, Laurence CO, Melaku YA, et al. Trends and causes of maternal mortality in Ethiopia during 1990-2013: findings from the Global Burden of Diseases study 2013. BMC public health. 2017;17(1):160.

11. Tessu M, Lamaro T, Henok A. Prevalence of Institutional Delivery among Mothers in Kometa Sub-Locality, Mizan-Aman Town, Southwest Ethiopia. Health Science Journal. 2016;10(1):1.

12. Wodaynew T, Fekecha B, Abdisa B. Magnitude of Home Delivery and Associated Fac-tors among Antenatal Care Booked Mothers in Delanta District, South Wollo Zone, North East Ethiopia: A Cross-Sectional Study, March 2018. Int J Womens Health Wellness. 2018;4(086)2474. 
13. Dhakal P, Shrestha M, Baral D, et al. Factors affecting the place of delivery among mothers residing in Jhorahat VDC, Morang, Nepal. International journal of community based nursing and midwifery. 2018;6(1):2.

14. Kucho B, Mekonnen N. Delivery at home and associated factors among women in child bearing age, who gave birth in the preceding two years in Zala Woreda, southern Ethiopia. J Public Health Epidemiol. 2017;9(6):177-188.

15. Abdella M, Abraha A, Gebre A, et al. Magnitude and Associated Factors for Home Delivery Among Women Who Gave Birth in Last 12 Months in Ayssaita, Afar, Ethiopia-2016. A Community Based Cross Sectional Study. Glob J Fertil Res. 2017;2(1):30-39.
16. Mekonnen Y, Ayichiluhm M, Dejenu G. Prevalence and determinants of home birth after AnteNatal Care attendance in Gozamin District, Northwest Ethiopia. Health Science Journal. 2015;9(6):1.

17. Adewuyi EO, Khanal V, Zhao Y, et al. Home childbirth among young mothers aged 15-24 years in Nigeria: a national population-based crosssectional study. BMJ open. 2019;9(9):e025494.

18. Wachs LS, Nunes BP, Soares MU, et al. Prevalence of home care and associated factors in the Brazilian elderly population. Cadernos de saude publica. 2016;32(3). 